\title{
Paired-associate learning as a function of the number of pre-experimental associative links'
}

\author{
Bertram E. Garskof and Tommie M. Bryan \\ RUTGERS, THE STATE UNIVERSITY
}

\begin{abstract}
Abstraet
Each of the four groups of Ss learned a five pair P-A list. Lists varied in number of word association links between S-R items. Ease of learning was found to relate directly to the degree of associative linkage present in each list.
\end{abstract}

\section{Problem}

Postman (1962) found that the degree of direct word association strength between $\mathrm{S}$ and $\mathrm{R}$ members of items in a P-A list did not affect learning of the lists when stimuli were highly frequent words. Postman suggested that frequent words possess so many potential links to the response words that the strengths of the direct links are irrelevant in the learning of the pairs.

The degree of associative overlap between two words is a measure of the total number of associative links between the words (Garskof \& Houston, 1963). It seems reasonable to infer that the degree of associative overlap might be related to the ease of learning of word pairs. The present experiment was designed to test the hypothesis that the ease of learning P-A lists would vary directly with the degree of associative overlapbetween members of the word pairs on the lists.

\section{Method}

Four P-A lists of five pairs each were developed based on associative overlap norms $(N=16)$ gathered in accord with a procedure described in Garskof \& Houston (1963) called the Relatedness Coefficient or RC. The four lists will be designated the high RC, medium $\mathrm{RC}$, low $\mathrm{RC}$ and zero $\mathrm{RC}$ lists with the mean $\mathrm{RC}$ values for these lists being $.426, .202, .087$, and .000 respectively.

No member of any pair in the experiment was given as a direct association to the other member of the pair by more than 18 out of 1008 Ss in the Russell-Jenkins norms (1954). There was minimum inter-item direct and overlap associative strength. None of the words used was low enough in word frequency (Thorndike \& Lorge, 1944) to be included in Postman's (1962) low frequency category with all but one word in his medium frequency category.

Fourteen Rutgers University female undergraduates were assigned randomly to each list condition. Standard P-A list construction procedures and instructions were adopted. Ss were run to a criterion of one perfect repetition of the list. A 1:1 interval was used for list presentation on a Lafayette model 303A memory drum.

\section{Results}

Table 1 shows the mean number of trials to criterion for each list.

An analysis of variance yielded a significant treatment effect $(\mathrm{F}=8.39 ; \mathrm{df}=3.52 ; \mathrm{P}<.01)$. The Lindquist procedure $(1953$, p. 93) was employed to test the differences between list means. The high, medium and low RC lists differed significantly $(\mathrm{P}<.05)$ from the zero RC list. The other comparisons were non-significant.

\section{Diseussion}

Although the differences between the lists were for the most part non-significant, the uniformity in the direction of the obtained differences suggests that degree of associative overlap influenced the learning of the experimental lists. This finding supports the notion that the total number of associative links between a word pair is an important determinant of the ease with which a pair is learned in P-A anticipation learning. Further research will address itself to the investigation of the effect of associative overlap where there is a strong direct associative link present.

Table 1

Mean Number of Trials to Criterion

for High, Medium, Low, and Zero RC Lists

$\begin{array}{llcc}\begin{array}{c}\text { High } \\ (\mathrm{N}=14)\end{array} & \begin{array}{c}\text { Medium } \\ (\mathrm{N}=14)\end{array} & \begin{array}{c}\text { Low } \\ (\mathrm{N}=14)\end{array} & \begin{array}{c}\text { Zero } \\ (\mathrm{N}=14)\end{array} \\ 2.86 & 3.71 & 5.07 & 10.86\end{array}$


GARSKOF, B. E., \& HOUSTON, J. P. Measurement of verbal relatedness: an idiographic approach. Psychol. Rev., 1963, 70, 277-288.

LINDQUIST, E. F. Design and analysis of experiments in psychology and education. Boston: Houghton Mifflin, 1953.

POSTMAN, L. The effects of language habits on the acquisition and retention of verbal associations. J. exp. Psychol., 1962, 64, 7-19.

RUSSELL, W. A., \& JENKINS, J. J. The complete Minnesota norms for responses to 100 words from the Kent-Rosanoff word association test. Tech. Rep. No. 11, SNonr 66216, Univer. of Minnesota, 1954. THORNDIKE, E. L., \& LORGE, I. A teacher's word book of 30,000 words. New York: Teacher's College, Columbia University, Bureau of Publication, 1944.

\section{Note}

1. This research was supported by Grant MH8448 from the National Institute of Mental Health. 